\title{
Unveiling novel inhibitors of dopamine transporter via in silico drug design, molecular docking, and bioavailability predictions as potential antischizophrenic agents
}

Sabitu Babatunde Olasupo ${ }^{1 *}$, Adamu Uzairu², Gideon Adamu Shallangwa² and Sani Uba²

\begin{abstract}
Background: The inhibition of dopamine transporter is known to play a significant role in the treatment of schizophrenia-related and other mental disorders. In a continuing from our previous study, computational drug design approach, molecular docking simulation, and pharmacokinetics study were explored for the identification of novel inhibitors dopamine transporter as potential Antischizophrenic agents. Consequently, thirteen (13) new inhibitors of dopamine transporter were designed by selecting the molecule with serial number 39 from our previous study as the template molecule because it exhibits good pharmacological attributes.

Results: Molecular docking simulation results revealed excellent molecular interactions between the protein target (PDB: 4m48) and the ligands (designed inhibitors) with major interactions that involved hydrogen bonding and hydrophobic interactions. Also, some of the designed inhibitors displayed a superior binding affinity range from - 10.0 to $-10.7 \mathrm{kcal} / \mathrm{mol}$ compared to the referenced drug (Lumateperone) with a binding affinity of $-9.7 \mathrm{kcal} / \mathrm{mol}$. Computed physicochemical parameters showed that none of the designed inhibitors including the referenced drug violate Lipinski's rule of five indicating that all the designed inhibitors would be orally bioavailable as potential drug candidates. Similarly, the ADMET/pharmacokinetics evaluations of some designed inhibitors revealed that they possessed good absorption, distribution, metabolism and excretion properties and none of the inhibitors is neither carcinogens nor toxic toward human ether-a-go-go related gene (hERG I) inhibitor or skin sensitization. Likewise, the BOILED-Egg graphics unveils that all the designed inhibitors demonstrate a high probability to be absorbed by the human gastrointestinal tract and could permeate into the brain. Besides, the predicted bioactive parameters suggested that all the selected inhibitors would be active as drug candidates. Furthermore, the synthetic accessibility scores for all the selected inhibitors and referenced drug lied within the easy zone (i.e., between 1-4) with their computed values range from 2.55 to 3.92, this implies that all the selected inhibitors would be very easy to synthesize in the laboratory.
\end{abstract}

Conclusions: Hence, all the designed inhibitors having shown excellent pharmacokinetics properties and good bioavailabilities attributes with remarkable biochemical interactions could be developed and optimized as novel Antischizophrenic agents after the conclusion of other experimental investigations.

Keywords: ADMET, Inhibitor, Dopamine, Receptor, Disorder, Schizophrenia

\footnotetext{
* Correspondence: olasabit@yahoo.com

1 National Agency for Food and Drug Administration and Control (NAFDAC),

Abuja, Nigeria

Full list of author information is available at the end of the article
}

\section{Springer Open}

(-) The Author(s). 2021 Open Access This article is licensed under a Creative Commons Attribution 4.0 International License, which permits use, sharing, adaptation, distribution and reproduction in any medium or format, as long as you give appropriate credit to the original author(s) and the source, provide a link to the Creative Commons licence, and indicate if changes were made. The images or other third party material in this article are included in the article's Creative Commons licence, unless indicated otherwise in a credit line to the material. If material is not included in the article's Creative Commons licence and your intended use is not permitted by statutory regulation or exceeds the permitted use, you will need to obtain permission directly from the copyright holder. To view a copy of this licence, visit http://creativecommons.org/licenses/by/4.0/. 


\section{Background}

Dopamine transporter (DAT) is a member of monoamine transporters that regulates dopamine (DA) neurotransmission, and it is also involved in various physiological functions and certain mental disorders [1]. DAT is a building block membrane protein functioning to remove dopamine from the synaptic cleft and accumulates it in surrounding cells, thus ending the signal of the neurotransmitter. Excessive neurotransmission of dopamine is a clinical condition termed by disordered thought commonly known as schizophrenia [2, 3]. Schizophrenia is a chronic neuropsychiatric disorder with reduced cognitive flexibility as a major symptom, other positive or residual symptoms may include hallucinations, delusions, anti-social behaviors suspiciousness, incoherent speech, strange, and dangerous altitudes [2]. Mental disorders associated with immoderate neurotransmission of dopamine levels by implicating DAT as well as dysfunction of dopamine (DA) neurotransmission are important contributing factors in the pathophysiology of neuropsychiatric disorders such as depression, bipolar disorder, Parkinson's disease, and attention deficit hyperactivity disorder (ADHD) [3]. The inhibition of DAT blocks the reuptake of dopamine from extracellular space into the synapse thereby raising the quantity of dopamine availability which in turns improves the possibility of dopamine receptor activation; however, the inhibition by most of the DAT inhibitors is limited with associated adverse side effects [4, 5]. Generally, drugs targeting the dopamine transporter (DAT) are majorly used to improve cognitive abilities as therapeutic agents for schizophrenia-related cognitive impairments and other neuropsychiatric disorders [6]. Many antipsychotics also known as neuroleptics medications such as Lumateperone, Modafinil, Chloropromazine Cariprazine, Risperidon are available as a class of compounds with a strong affinity for various subtypes of dopamine receptors for the treatment of schizophrenic patients to decrease excess levels of dopamine thereby lessen the positive symptoms of the disorder but none of the beneficial effects for any of the medication strategies were considered to be of clinically significant [2, 7]. Also, the mechanism of actions of many of these drugs remained unresolved [6]. Therefore, the need to design new inhibitors of DAT having more therapeutic potential with lower or no side effects as antischizophrenic agents is calling for global attention.

In a continuous effort to our previous study [2], computer-aided structure-based drug design, virtual screening, and in silico pharmacokinetics predictions were procured for the present study as a time saving and cost-effective approaches for the identification of novel inhibitors of DAT with better therapeutic potential for the treatment of schizophrenia-related cognitive impairments and other neuropsychiatric disorders. This method stems from the fact that the structure-based drug design approach has been widely applied in the analysis of molecular recognition through binding affinities, molecular interactions, induced conformational changes, and toxicity filters for the design and identification of novel compounds containing important physicochemical properties due to efficient structural adjustment/modification in the design of new molecules [8].

\section{Methods}

\section{Computational drug design approach}

In a continuation from our previous work [2], computational drug design technique was employed to design and identify novel inhibitors of dopamine transporter (DAT) of better therapeutic properties that could serve as potential antipsychotic agents for schizophreniarelated mental disorders. Template compound was selected from the previous work for the design of new inhibitors of DAT. Chemdraw software ultra-version 12.0 was used to sketch the $2 \mathrm{D}$ molecular structures of the hypothetical designed inhibitors while Spartan 14 software was employed for the geometric optimization after converting the $2 \mathrm{D}$ structures to three-dimensional (3D) structures. Each molecule was initially optimized with the molecular mechanics via MMFF (molecular mechanics force field) and subsequently re-optimized by density functional theory (DFT) using the $\mathrm{B}_{3} \mathrm{LYP} / 6$ $31 \mathrm{G} *$ basis set with the aid of Spartan 14 Version 1.1.0 software. The optimized molecules were then saved in pdb file format via Spartan 14 software as prepared ligands for molecular docking study. The prepared ligands were docked with the prepared structure of dopamine transporter (target protein) using PyRx software via AutoDock Vina 4.2 version software. The docking results were visualized and analyzed with the aid of Discovery Studio Visualizer software 2020 version [9, 10]. Molecular docking, ADMET/pharmacokinetics predictions, and bioactive evaluation were further performed on the new designed compounds (inhibitors of dopamine transporter). The 2D chemical structures of template molecule and some designed inhibitors are shown in Fig. 1.

\section{Selection of template molecule and design of new inhibitors of dopamine transporter}

The molecule with serial number 39 as contained in Supplementary Table SD1 of the dataset used in our previous study [2] was selected as the template molecule to design hypothetical inhibitors of DAT using structure-based drug design (SBDD) approach. The template molecule was selected owing to its superior quality assurance features such that it fell within the 
<smiles>N#Cc1ccc2[nH]c(CN3CCN(c4ccc(Cl)cc4)CC3)cc2c1</smiles>

Template molecule<smiles>N#Cc1ccc2[nH]c(CN3CCN(c4cc(Cl)cc(Cl)c4)CC3)cc2c1</smiles>

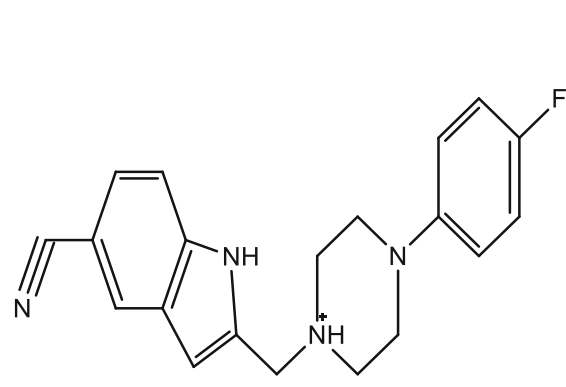<smiles>Cc1ccc(N2CCN(Cc3cc4cc(C#N)ccc4[nH]3)CC2)cc1C</smiles>

$39 \mathrm{c}$

Fig. 1 2D structure of template molecule and some designed inhibitors (39b, 39c, and 39g)

applicability domain with low standard residual value, it has relatively better inhibitory activity and good binding affinity and above all, and it possesses remarkable druglike property because it fulfilled Lipinski's rule of five (RO5) for a pharmacologically active compound [11].

\section{Preparation of the target protein and ligands}

The dopamine transporter protein (DTP) is responsible in maintaining dopamine levels via the reuptake of dopamine in neuronal cells. Dopamine is generated in the presynaptic neuron and moved to the synaptic cleft, where it can bind to dopamine receptors on the postsynaptic neuron. DAT disallows dopamine accumulation by removing unbound dopamine molecules from the synaptic cleft [12]. Three-dimensional structure of the protein (PDB code: 4M48) retrieved from Protein Data Bank site (http://www.rcsb.org/pdb) was prepared by adding hydrogen atoms (protonation) and removing all bound ligands and other heteroatoms by using the Discovery Studio Visualizer 2016 version [2] and subsequently saved in pdb file format for molecular docking simulation processes. Similarly, designed inhibitors (ligands) were prepared by transforming 2D molecular structures to 3D structures for energy minimization (optimization) using Spartan 14 software at DFT [13]. The optimized 3D structures of the designed inhibitors were then saved in pdb file format as prepared ligands. Figure $2 \mathrm{a}$ and $\mathrm{b}$ represent $3 \mathrm{D}$ structures of the prepared receptor and a ligand (designed compound $39 \mathrm{~g}$ ) respectively.

\section{Molecular docking analysis and virtual screening}

Molecular docking simulation was performed to estimate the binding affinity (scoring function), and visualize and evaluate receptor-ligand interactions in order to examine the binding mode and activity of the ligand. PyRx software via AutoDock Vina 4.2 version and Discovery Studio Visualizer software 2020 version were used to generate the scoring functions (binding affinities) and visualize protein-ligand interactions 


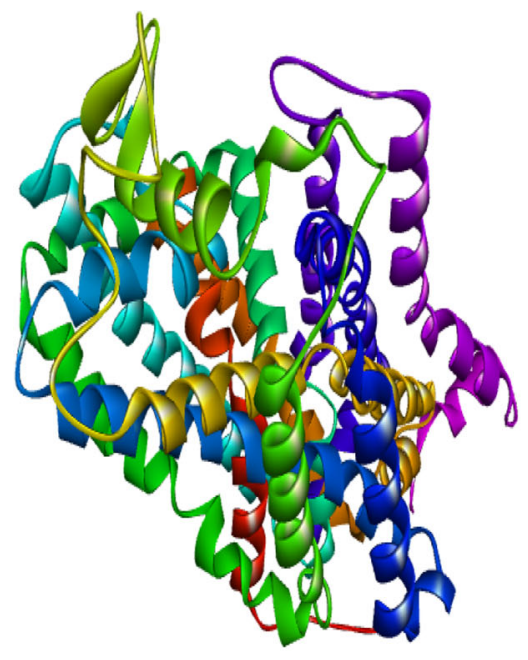

$A$

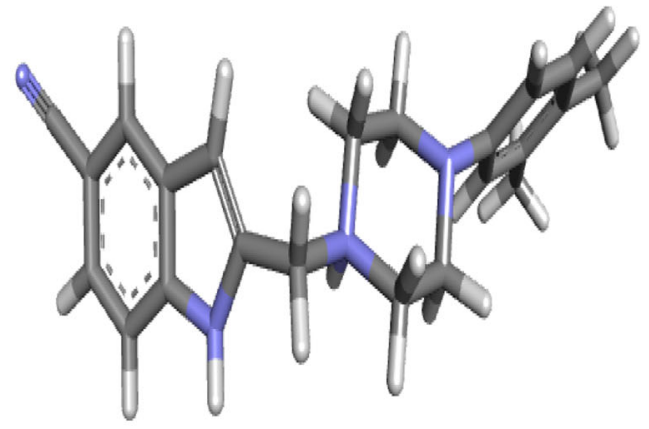

$\boldsymbol{B}$

Fig. 2 a 3D structure of the prepared protein target (PDB: 4m48) and $\mathbf{b} 3 \mathrm{D}$ structure of a prepared ligand 39g

involving non-bonding polar and hydrophobic interactions [13].

\section{ADMET/pharmacokinetics predictions and bioactive evaluation}

Absorption, distribution, metabolism, excretion and toxicity (ADMET) properties and other pharmacokinetics parameters are critical attributes and stages for any compound to pass through prior to be optimized and developed as drug candidates which must be carefully investigated [14]. In the present study, SwissADME (http://www.swissadme.ch/index.php), admetSAR 2.0 (http://lmmd.ecust.edu.cn/admetsar2), pkCSM (http://biosig.unimelb.edu.au/pkcsm/prediction), and Molinspiration (https://www.molinspiration.com/cgibin/properties) were procured as online web tools/ software to predict the ADMET/pharmacokinetics properties, profile the physicochemical parameters [15-17], and compute the bioactive scores of the designed inhibitors [18].

\section{Results}

Tables and figures are shown in this section.

\section{Discussion}

\section{Computational drug design of new inhibitors of dopamine transporter}

Pharmacophore is a molecular framework or a structural feature in a molecule that is recognized at the receptor site which is responsible for the pharmacological or biological activity of a molecule [19]. Structural modification of a template molecule using most important pharmacophores by incorporating or removing $\mathrm{H}$-bond donor or $\mathrm{H}$-bond acceptor or hydrophobic substituents was applied in the computational drug design of the new inhibitors that could improve its molecular interactions with the biological target [19]. 2D structures of the newly designed 13 molecules (inhibitors of dopamine transporter) were reported in Supplementary Table DS2. The impact of activating groups $\left(-\mathrm{NH}_{2},-\mathrm{OH},-\mathrm{OCH}_{3}\right.$, $-\mathrm{COOH}$, and $\left.-\mathrm{CH}_{3}\right)$ in the designed compounds were significantly felt compare to the deactivating substituents $\left(-\mathrm{NO}_{2},-\mathrm{CF}_{3},-\mathrm{F}\right.$, and $\left.\mathrm{Cl}\right)$ evidenced from the obtained result of binding affinity or biochemical interactions between the receptor and the designed compounds (Supplementary Table DS2). The electron-donating property of the pharmacophores using activating groups could account for an increase in electron density thereby led to improve the reactivity of the compound via the molecular interactions with the biological target in contrast to the deactivating substituents which decrease the reactivity by withdrawing electron density from a compound as observed in the designed compounds [20].

\section{Molecular docking investigation of the new inhibitors of dopamine transporter}

A molecular docking simulation study of the designed inhibitors was investigated on the receptor (PDB code: $4 \mathrm{~m} 48)$ to determine the types of amino acid residues responsible for the biochemical interaction at the binding site. The computed binding affinities for all the designed compounds ranges from -9.5 to $-10.7 \mathrm{kcal} / \mathrm{mol}$ while the binding affinity of a referenced drug (Lumateperone) was calculated to be $-9.7 \mathrm{kcal} / \mathrm{mol}$ (Supplementary Table DS2). This implies that almost all the designed compounds showed remarkable biochemical interactions 
at the binding site of the protein target. Using the Discovery Studio Visualizer software, some of the designed compounds were visualized to examine the type of molecular interactions and amino acid residues responsible for the observed biochemical interactions at the binding site of the receptor. The result of molecular docking simulation for some designed compounds and a referenced drug (Lumateperone) is presented in Table 1. From the result (Table 1), the binding affinity for all the selected compounds range from -10.00 to $-10.70 \mathrm{kcal} /$ mol compared to Lumateperone (Referenced drug) with the binding energy of $-9.70 \mathrm{kcal} / \mathrm{mol}$. More so, the observed number of amino acid residues associated with hydrogen bonding and hydrophobic interactions were conspicuously higher in all the selected compounds with shorter hydrogen bond length (less than $3.0 \AA$ A ) compared to Lumateperone with only one amino acid residue Phenylalanine (PHE319) linked to hydrogen bonding at a higher bond length of $3.52 \AA$.

Similarly, all the selected compounds revealed good biochemical interactions with the target protein by forming strong hydrogen bonding with a unique amino acid residue Arginine (ARG52) at different bond lengths. Compound $39 \mathrm{~g}$ and $39 \mathrm{~m}$ were discovered to possess the highest binding affinity $(-10.70$ and $-10.6 \mathrm{kcal} / \mathrm{mol} \mathrm{re}-$ spectively) with superior hydrophobic interactions at the binding site of the receptor in addition to amino acid residue Arginine (ARG52) connected to hydrogen bonding of shorter bond lengths and electrostatic interactions with amino acid residue Aspartic acid (ASP475). The outstanding biochemical interactions and higher binding affinity could be linked to the observed structural differences in the compounds (39g and $39 \mathrm{~m}$ ) due to electrophilic aromatic substitution (activating substituents $-\mathrm{CH} 3$ ) at para-positions in the two compounds
(Supplementary Table DS2). Figure 3a and b show 2D and 3D interactions of the compounds $39 \mathrm{~g}$ and $39 \mathrm{~m}$ between the receptor while Fig. 3c depicts the docking pose of compound $39 \mathrm{~g}$ showing hydrogen bonding and hydrophobic interactions with the protein target.

\section{ADMET /Pharmacokinetics properties and drug-likeness predictions of the designed inhibitors of dopamine transporter}

In some cases, the best-docked compounds are often considered as potential drug candidates based on their binding affinity; however, it is more important to evaluate some critical pharmacokinetic parameters or ADME $\mathrm{T}$ properties (absorption, distribution, metabolism, excretion, and toxicity) as most significant attributes by using appropriate steps in drug design, development, and discovery adventures [21, 22]. For these reasons, physicochemical parameters of all the designed compounds (Table 2) and ADMET properties of some selected compounds (Table 3) were carefully investigated by utilizing some online web-based software [15-17] and the obtained results were compared with a referenced drug (Lumateperone). The predicted physicochemical parameters which play a very important role in a molecule efficacy, safety, or metabolism were evaluated for all the designed compounds using Lipinski's rule of five (RO5) as reported in Table 2; the result showed that none of the designed compounds including the referenced drug (Lumateperone) violates Lipinski's rule of five (RO5). This suggests that all the designed inhibitors possessed good attributes of drug-like or pharmacological properties which could make them orally bioavailable $[11,13]$.

Likewise, the predicted ADMET properties for some selected compounds were presented in Table 3. From

Table 1 Types of interactions and amino acid residues between the target protein and some designed inhibitors

\begin{tabular}{|c|c|c|c|c|}
\hline $\mathrm{S} / \mathrm{N}$ & $\begin{array}{l}\text { Binding } \\
\text { affinity (kcal/mol) }\end{array}$ & $\begin{array}{l}\text { Hydrogen bonding and } \\
\text { amino acid residues with } \\
\text { bond length }(\AA)\end{array}$ & $\begin{array}{l}\text { Hydrophobic interactions } \\
\text { and amino acid residues }\end{array}$ & $\begin{array}{l}\text { Other interactions } \\
\text { and amino acid } \\
\text { residues }\end{array}$ \\
\hline $39 b$ & -10.5 & $\begin{array}{l}\text { ARG52 (2.38665) } \\
\text { ARG52 (2.46439) }\end{array}$ & $\begin{array}{l}\text { PHE319, PHE319 } \\
\text { ILE1 16, ALA117, ALA117 } \\
\text { ILE1 16, ILE483, PHE43, PHE325, ALA117, VAL120 }\end{array}$ & $\begin{array}{l}\text { ASP475 } \\
\text { (Electrostatic) }\end{array}$ \\
\hline $39 c$ & -10.2 & $\begin{array}{l}\text { ARG52 (2.28487) } \\
\text { ARG52 (2.36122) }\end{array}$ & PHE319, PHE319, PHE325, ALA48, ALA117, VAL120 & $\begin{array}{l}\text { ASP46 } \\
\text { (Electrostatic) } \\
\text { PHE325 (Halogen) }\end{array}$ \\
\hline $39 f$ & -10 & $\begin{array}{l}\text { ARG52 (2.42665) } \\
\text { ARG52 (2.30477) }\end{array}$ & $\begin{array}{l}\text { PHE319, PHE319, ALA117 } \\
\text { ALA428, VAL327, ALA48, ARG52, ALA117, VAL120 }\end{array}$ & - \\
\hline $39 \mathrm{~g}$ & -10.7 & $\begin{array}{l}\text { ARG52(2.39222) } \\
\text { ARG52 (2.52234) }\end{array}$ & $\begin{array}{l}\text { PHE319, PHE319, THR315, GLN316, ALA117, ALA117 } \\
\text { ALA428, VAL327, ILE116, PHE325, ALA117, VAL120 }\end{array}$ & $\begin{array}{l}\text { ASP475 } \\
\text { (Electrostatic) }\end{array}$ \\
\hline $39 m$ & -10.6 & $\begin{array}{l}\text { ARG52 (2.40652) } \\
\text { ARG52 (2.45719) }\end{array}$ & $\begin{array}{l}\text { PHE319, PHE319, PHE325 } \\
\text { ALA117, ALA479, LE483, VAL327, PHE319, PHE325 } \\
\text { ALA117, VAL120 }\end{array}$ & $\begin{array}{l}\text { ASP475 } \\
\text { (Electrostatic) }\end{array}$ \\
\hline $\begin{array}{l}\text { Lumateperone } \\
\text { (Referenced drug) }\end{array}$ & -9.7 & PHE319 (3.52353) & $\begin{array}{l}\text { PHE319, PHE325, ALA48 } \\
\text { ARG52, PHE319, PHE319, ALA117, VAL120 }\end{array}$ & PHE325 (Halogen) \\
\hline
\end{tabular}




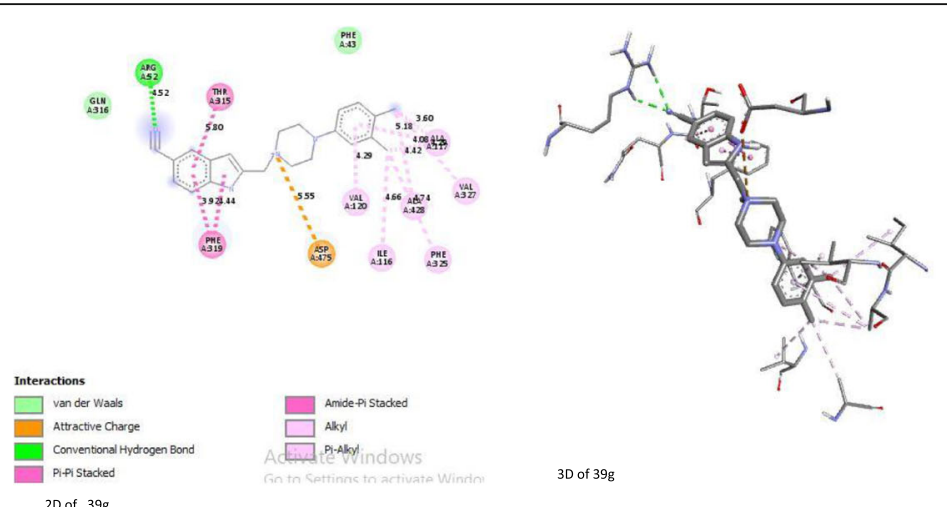

(A)

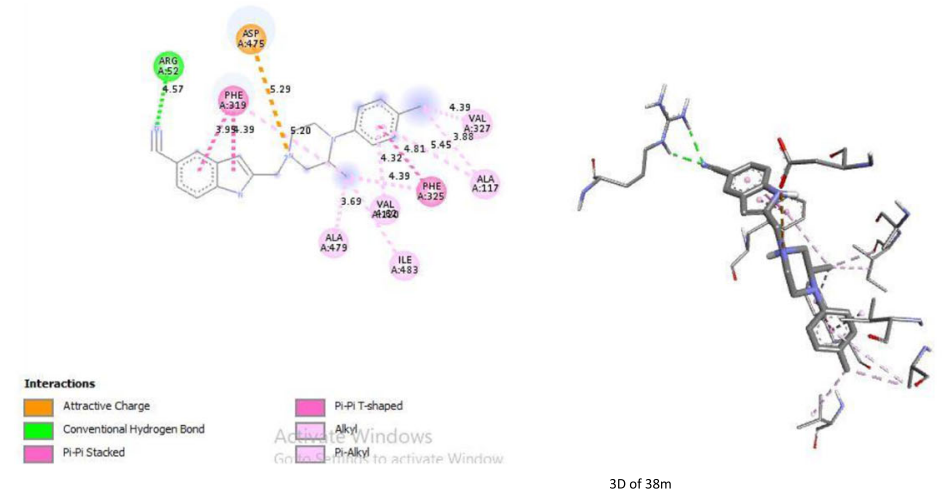

(B)
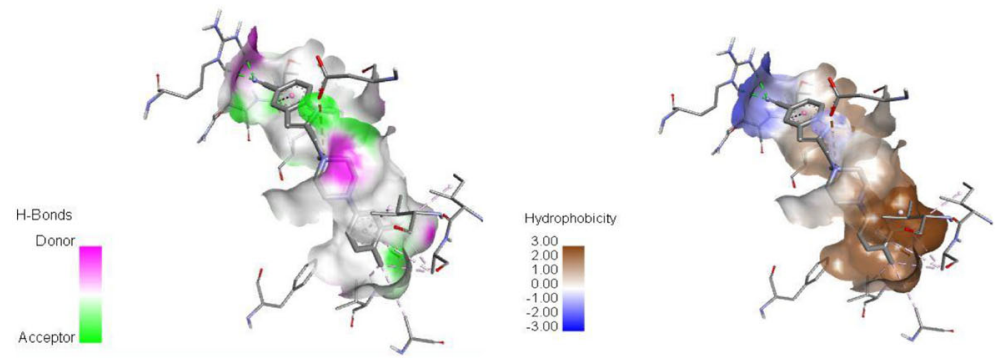

(C)

Fig. 3 Panels $\mathbf{a}$ and $\mathbf{b}$ are $2 \mathrm{D}$ and $3 \mathrm{D}$ interactions of the compounds $39 \mathrm{~g}$ and $39 \mathrm{~m}$ between the target protein while panel $\mathbf{c}$ is the docking pose of compound $39 \mathrm{~g}$ showing hydrogen bonding and hydrophobic interactions between the protein

ADMET predictions, the computed parameters for absorption properties revealed to be within the threshold values (\%Human Intestinal absorption $>30 \%$, Caco2 permeability $>0.90$, and Skin Permeability $\operatorname{logKp}>-2.5)$ and all the selected compounds including the referenced drug were found to be P-glycoprotein II inhibitors. This implies that all the selected compounds possessed excellent pharmacological properties with good human intestinal absorption [23, 17]. Similarly, the predicted permeability values for both blood-brain barrier (BBB) and central nervous system (CNS) and other predicted properties (metabolic and excretion) suggested that all the selected compounds (Table 3 ) have good therapeutic potentials as inhibitors of dopamine transporte $r[17]$. A compound with $\mathrm{BBB}$ value of $\log \mathrm{BB}$ greater than 0.3 is considered as highly absorbing to the central nervous system (CNS) [24, 17]. Luckily enough, all the selected compounds including the referenced drug have computed $\mathrm{BBB}$ value of $\log \mathrm{BB}$ greater than 0.3 as reported in the table. Furthermore, the pharmacokinetic assessment of Cytochrome P450 inhibitions showed that all the selected compounds are noninhibitors of CYP2C19, CYP2C9, and CYP3A4 but as inhibitors of CYP2D6 enzyme including the referenced drug.

In like manner, human intestinal absorption (HIA), the brain penetration, and medicinal properties for all 
Table 2 Predicted physicochemical parameters of the designed inhibitors and a referenced drug (Lumateperone)

\begin{tabular}{|c|c|c|c|c|c|c|c|c|c|}
\hline$S / N$ & $\begin{array}{l}\text { Molecular } \\
\text { formula }\end{array}$ & $\begin{array}{l}\text { Molecular } \\
\text { weight } \mathrm{g} / \mathrm{mol}\end{array}$ & $\begin{array}{l}\text { No of } \\
\text { rotatable bonds }\end{array}$ & $\begin{array}{l}\text { No of H-bond } \\
\text { acceptors }\end{array}$ & $\begin{array}{l}\text { No of H-bond } \\
\text { donors }\end{array}$ & $\begin{array}{l}\text { Total polar } \\
\text { surface area }\end{array}$ & AlogP & WLOGP & $\begin{array}{l}\text { Lipinski } \\
\text { violations }\end{array}$ \\
\hline $39 a$ & $\mathrm{C} 2 \mathrm{OH} 21 \mathrm{~N} 4$ & 317.41 & 3 & 1 & 2 & 47.26 & 1.94 & 1.03 & 0 \\
\hline 39b & $\mathrm{C} 2 \mathrm{OH} 19 \mathrm{Cl} 2 \mathrm{~N} 4$ & 386.3 & 3 & 1 & 2 & 47.26 & 3.25 & 2.34 & 0 \\
\hline $39 c$ & $\mathrm{C} 2 \mathrm{OH} 2 \mathrm{OFN} 4$ & 335.4 & 3 & 2 & 2 & 47.26 & 2.08 & 1.59 & 0 \\
\hline $39 d$ & $\mathrm{C} 21 \mathrm{H} 20 \mathrm{~F} 3 \mathrm{~N} 4$ & 385.41 & 4 & 4 & 2 & 47.26 & 2.96 & 3.2 & 0 \\
\hline $39 e$ & $\mathrm{C} 2 \mathrm{OH} 2 \mathrm{ON} 5 \mathrm{O} 2$ & 362.41 & 4 & 3 & 2 & 93.08 & 1.85 & 0.94 & 0 \\
\hline $39 f$ & $\mathrm{C} 21 \mathrm{H} 23 \mathrm{~N} 4$ & 331.43 & 3 & 1 & 2 & 47.26 & 2.25 & 1.34 & 0 \\
\hline $39 g$ & $\mathrm{C} 22 \mathrm{H} 25 \mathrm{~N} 4$ & 345.46 & 3 & 1 & 2 & 47.26 & 2.56 & 1.65 & 0 \\
\hline $39 h$ & $\mathrm{C} 2 \mathrm{OH} 21 \mathrm{~N} 4 \mathrm{O} 3$ & 365.41 & 3 & 4 & 5 & 107.95 & 1.06 & 0.15 & 0 \\
\hline $39 i$ & $\mathrm{C} 2 \mathrm{OH} 21 \mathrm{~N} 4 \mathrm{O}$ & 333.41 & 3 & 2 & 3 & 67.49 & 1.65 & 0.74 & 0 \\
\hline 39j & $\mathrm{C} 21 \mathrm{H} 23 \mathrm{~N} 4 \mathrm{O}$ & 347.43 & 4 & 2 & 2 & 56.49 & 1.95 & 1.04 & 0 \\
\hline $39 k$ & $\mathrm{C} 21 \mathrm{H} 29 \mathrm{~N} 4$ & 337.48 & 3 & 2 & 2 & 47.26 & 2.32 & 1.41 & 0 \\
\hline $39 \mid$ & $\mathrm{C} 21 \mathrm{H} 21 \mathrm{~N} 4 \mathrm{O} 2$ & 361.42 & 4 & 3 & 3 & 84.56 & 1.64 & 0.73 & 0 \\
\hline $39 m$ & $\mathrm{C} 22 \mathrm{H} 25 \mathrm{~N} 4$ & 345.46 & 3 & 1 & 2 & 47.26 & 2.64 & 1.73 & 0 \\
\hline $\begin{array}{l}\text { Lumateperone } \\
\text { (referenced drug) }\end{array}$ & $\mathrm{C} 24 \mathrm{H} 28 \mathrm{FN} 3 \mathrm{O}$ & 393.5 & 5 & 3 & 0 & 26.79 & 3.92 & 3.19 & 0 \\
\hline
\end{tabular}

the designed compounds and the standard drug (Lumateperone) were demonstrated by the BOILED Egg diagram as shown in Fig. 4 using Swiss ADME online software. The white region of the diagram (Fig. 4a) represents a region of the highest likelihood of being absorbed by the human gastrointestinal system while the yellow part (yolk) depicts the region of the highest probability to the brain penetration [25]. The diagram (Fig. 4a) revealed that most of the designed compounds including the standard drug (Lumateperone) reside within the yellow region (yolk). This is suggesting that all designed compounds possessed a high probability to be absorbed by the human gastrointestinal tract and permeate into the brain to reach the target enzyme $[13,26]$. Figure $4 \mathrm{~b}$ represents oral bioavailability radar chart for the designed compound 39g which relied on the 6 important physicochemical properties as displayed on the chart. All the designed compounds and the

Table 3 Predicted ADME/pharmacokinetics properties of some designed inhibitors

\begin{tabular}{|c|c|c|c|c|c|c|c|}
\hline \multirow[b]{2}{*}{ Properties } & \multirow[b]{2}{*}{ Parameters } & \multicolumn{5}{|c|}{ Some selected designed inhibitors } & \multirow{2}{*}{$\begin{array}{l}\text { Referenced drug } \\
\text { Lumateperone }\end{array}$} \\
\hline & & $39 b$ & $39 c$ & $39 f$ & $39 g$ & $39 m$ & \\
\hline \multirow[t]{5}{*}{ Absorption } & Water solubility & -3.761 & -3.362 & -3.386 & -3.483 & -3.363 & -4.03 \\
\hline & Caco2 permeability & 0.999 & 1.25 & 1.013 & 1.011 & 1.02 & 1.175 \\
\hline & Intestinal absorption (\% Absorbed) & 92.854 & 94.5 & 95.056 & 94.854 & 94.608 & 93.538 \\
\hline & Skin Permeability & -2.747 & -2.751 & -2.748 & -2.748 & -2.741 & -2.59 \\
\hline & P-glycoprotein II inhibitor & Yes & Yes & Yes & Yes & Yes & Yes \\
\hline \multirow[t]{4}{*}{ Distribution } & VDss (human) & 0.912 & 0.726 & 0.902 & 0.935 & 0.915 & 1.404 \\
\hline & Fraction unbound (human) & 0.241 & 0.251 & 0.238 & 0.225 & 0.237 & 0.071 \\
\hline & BBB permeability(log BB) & 0.339 & 0.337 & 0.357 & 0.37 & 0.43 & 0.676 \\
\hline & CNS permeability & -1.451 & -1.446 & -1.42 & -1.406 & -1.444 & -1.423 \\
\hline \multirow[t]{5}{*}{ Metabolism } & CYP1A2 inhibitor & Yes & Yes & Yes & Yes & Yes & No \\
\hline & CYP2C19 inhibitor & No & No & No & No & No & No \\
\hline & CYP2C9 inhibitor & No & No & No & No & No & No \\
\hline & CYP2D6 inhibitor & Yes & Yes & Yes & Yes & Yes & Yes \\
\hline & CYP3A4 inhibitor & No & No & No & No & No & Yes \\
\hline \multirow[t]{2}{*}{ Excretion } & Total clearance & 1.084 & 1.297 & 1.35 & 1.427 & 1.275 & 1.095 \\
\hline & Renal OCT2 substrate & Yes & Yes & Yes & Yes & Yes & Yes \\
\hline
\end{tabular}




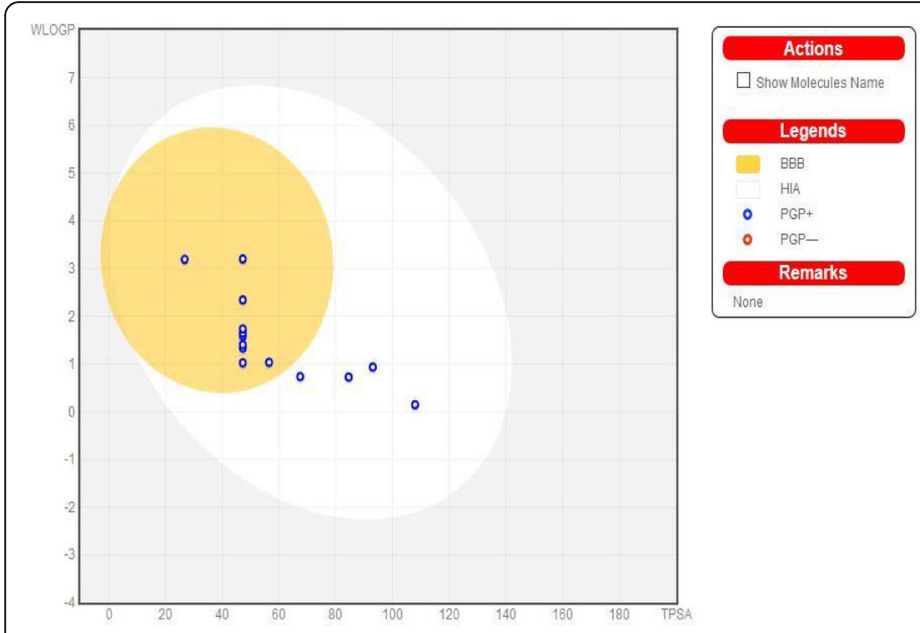

A

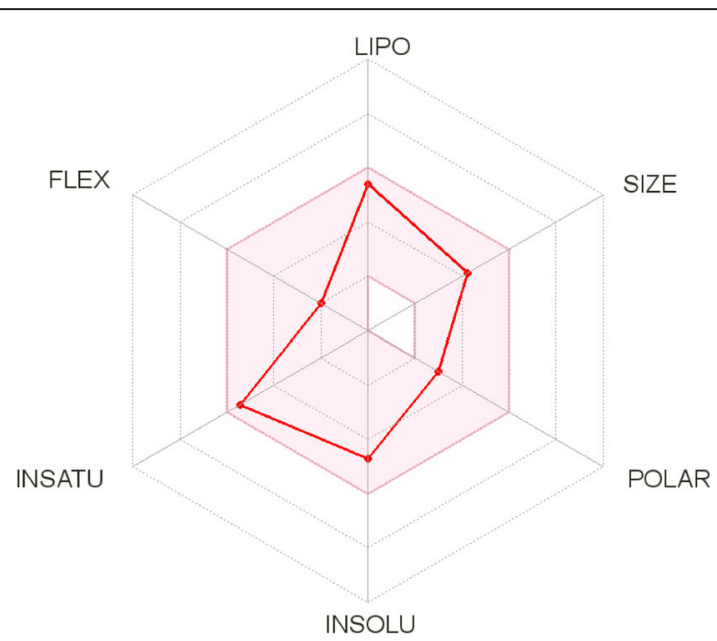

B

Fig. 4 a BOILED-Egg diagram for all the designed compounds including the referenced drug and $\mathbf{b}$ bioavailability radar chart for compound $39 \mathrm{~g}$

standard drug proved to exhibit a good physiochemical profile because their predicted parameters lied within the limit [14].

\section{Predicting bioactivity score, in silico toxicology, and medicinal chemistry properties of some designed inhibitors of dopamine transporter}

Bioactivity, toxicity, and medicinal chemistry properties of some designed compounds were further investigated using the online based web tools $[18,17]$. Table 4 represents predicted bioactivity scores and medicinal chemistry properties while Table 5 shows the in silico toxicity profiles of some designed compounds. The bioactivity scores of G protein-coupled receptor (GPCR) ligand, ion channel modulator, nuclear receptor ligand, kinase inhibitor, and enzyme inhibitor were evaluated for the selected compounds. A compound is considered to be more bioactive if the predicted value is greater than 0.00
$(>0)$, moderate active if the value lies between -0.5 and 0.00 while a compound is assumed to be non-active if the predicted value is less than -0.5 [27]. Remarkably, all the selected compounds including the referenced drug are very active to $G$ protein-coupled receptor (GPCR) ligand because the predicted bioactive values are greater than 0.00 as reported in Table 4. Similarly, the predicted PAINS alerts (pan assay interference) and synthetic accessibility for medicinal chemistry properties were also examined. The results (Table 4) revealed that only two of the selected (39b and 39c) including the referenced drug have no alert (PAINS alert $=0$ ) while the remaining compounds (39f, 39g, and 39m) displayed alerts of one (PAINS alert $=1$ ). Thus, compounds 39b and 39c possessed no attributes that would provide false positive biological assays for the compounds [14]. Also, a synthetic accessibility or complexity score of 1-4 indicates easy, 4-7 medium, and 8-10 hard/difficult to

Table 4 Predicted bioactivity scores and medicinal chemistry of some designed inhibitors

\begin{tabular}{|c|c|c|c|c|c|c|c|}
\hline \multirow[b]{2}{*}{ Predicted properties } & \multirow[b]{2}{*}{ Predicted Parameters } & \multicolumn{5}{|c|}{ Predicted variables of some newly designed inhibitors } & \multirow{2}{*}{$\frac{\text { Referenced drug }}{\text { Lumateperone }}$} \\
\hline & & $39 b$ & $39 c$ & $39 f$ & $39 g$ & $39 m$ & \\
\hline \multirow[t]{5}{*}{ Bioactivity score } & GPCR ligand & 0.24 & 0.25 & 0.2 & 0.19 & 0.21 & 0.32 \\
\hline & Ion channel modulator & 0.21 & 0.2 & 0.14 & 0.12 & 0.16 & -0.01 \\
\hline & Kinase inhibitor & 0.18 & 0.23 & 0.15 & 0.16 & 0.1 & -0.11 \\
\hline & Nuclear receptor ligand & 0.02 & 0.06 & 0.01 & 0.02 & 0.04 & -0.06 \\
\hline & Enzyme inhibitor & 0.11 & 0.15 & 0.11 & 0.09 & 0.1 & -0.08 \\
\hline Drug likeness & Lipinski violations & 0 & 0 & 0 & 0 & 0 & 0 \\
\hline \multirow[t]{2}{*}{ Medicinal chemistry } & PAINS alerts & 0 & 0 & 1 & 1 & 1 & 0 \\
\hline & Synthetic accessibility & 2.67 & 2.55 & 2.64 & 2.77 & 3.16 & 3.92 \\
\hline
\end{tabular}


Table $\mathbf{5}$ In silico toxicity profiles of some designed inhibitors

\begin{tabular}{|c|c|c|c|c|c|c|}
\hline \multirow[b]{2}{*}{ Toxicity properties } & \multicolumn{5}{|c|}{ Some newly designed inhibitors } & \multirow{2}{*}{$\begin{array}{l}\text { Referenced druc } \\
\text { Lumateperone }\end{array}$} \\
\hline & $39 b$ & $39 c$ & $39 f$ & $39 g$ & $39 m$ & \\
\hline AMES toxicity & Yes & Yes & Yes & Yes & No & Yes \\
\hline hERG I inhibitor & No & No & No & No & No & No \\
\hline Carcinogenicity & No & No & No & No & No & No \\
\hline Hepatotoxicity & No & Yes & Yes & Yes & No & Yes \\
\hline Skin sensitization & No & No & No & No & No & No \\
\hline
\end{tabular}

synthesize $[14,15]$. Interestingly, the synthetic accessibility scores for all the selected compounds and the referenced drug lied within the range of easy (i.e., 1-4) with their predicted values range from 2.55 to 3.92 ; this is a good indication that all the selected compounds would be very easy to synthesis in the laboratory [28].

\section{In silico toxicity prediction of some selected inhibitors of dopamine transporter}

Investigation and determination of intolerable toxicity properties of a drug candidate are extremely important prior to a drug candidate moves into clinical trials phase $[14,29]$. The investigated toxicity properties of some selected compounds (Table 5) revealed that none of the compounds including the referenced drug is carcinogens with no toxicity tendency toward human ether-a-go-go related gene (hERG I) inhibitor or skin sensitization. Conversely, all the selected inhibitors including the referenced drug exhibited AMES toxicity except compound $(39 \mathrm{~m})$ and also only compounds $39 \mathrm{~b}$ and $39 \mathrm{~m}$ that are not hepatotoxic (Table $5)$. Hence, the investigated toxicity profiles showed that most of the selected compounds would be safe with compound $39 \mathrm{~m}$ to be safer as potential drug candidates.

\section{Conclusion}

In this current study, in silico drug design approach was employed to design 13 new inhibitors of dopamine transporter by selecting the molecule with serial number 39 from our previous work as the template compound because it exhibits good pharmacological attributes. Molecular docking simulation was performed to examine the binding modes and the amino acids residues responsible for the biochemical interaction at the active site of the protein target (receptor) of PDB code $4 \mathrm{~m} 48$ and the ligands (designed inhibitors). The result of molecular docking revealed excellent biochemical interactions between the receptor and the designed inhibitors with major interactions that involved hydrogen bonding and hydrophobic interactions. Also, some of the designed inhibitors exhibited superior binding affinities range from - 10.0 to $-10.7 \mathrm{kcal} / \mathrm{mol}$ compared to the referenced drug (Lumateperone) with a binding affinity of -9.7 $\mathrm{kcal} / \mathrm{mol}$. To evaluate the drug-like profiles and pharmacological properties of the designed inhibitors, in silico pharmacokinetics properties and ADMET predictions were investigated. The computed physicochemical parameters showed that none of the designed inhibitors including the referenced drug violate Lipinski's rule of five, which means that all the designed inhibitors would be orally bioavailable and pharmacological active as potential drug candidates. Similarly, the ADMET properties of some designed inhibitors revealed that the selected inhibitors exhibit good absorption, distribution, metabolism, excretion properties, and none of the selected inhibitors is neither carcinogens nor toxic toward human ether-a-go-go related gene (hERG I) inhibitor or skin sensitization. Likewise, the BOILED-Egg graphics unveils all the designed inhibitors demonstrate a high probability to be absorbed by the human gastrointestinal tract and could easily permeate into the brain. The predicted bioactive parameters suggested that all the selected inhibitors would be very active as drug candidates. Furthermore, the synthetic accessibility scores for all the selected inhibitors and the referenced drug lied within the range of easy (i.e. between 1-4) because their predicted values lied between 2.55 to 3.92; thus, most of the designed inhibitors would be very easy to synthesize in the laboratory. Following these results, the designed inhibitors could be developed and optimized as novel therapeutic agents for the treatment of schizophrenia-related cognitive impairments and other neuropsychiatric disorders. However, further experimental investigations and clinical evaluations are recommended to examine the mechanisms of their actions and other pharmacological effects.

\section{Supplementary Information}

The online version contains supplementary material available at https://doi. org/10.1186/s43094-021-00198-3.

Additional file 1: Supplementary Table DS2. 2D structures, molecular docking results and some physicochemical parameters of the designed inhibitors. Supplementary Table SD1. 


\section{Abbreviations}

ADHD: Attention deficit hyperactivity disorder; BBB: Blood-brain barrier; CNS: Central nervous system; 2D: Two-dimensional structures; 3D: Threedimensional structures; DA: Dopamine; DAT: Dopamine transporter: DFT: Density functional theory; GPCR: Group protein-coupled receptor; PDB: Protein data bank; ADMET: Absorption, distribution, metabolism, excretion, and toxicity; hERG: Human ether-a-go-go related gene; HIA: Human intestinal absorption; RO5: Rule of five; PAINS: Pan assay interference; SBDD: Structure-based drug design

\section{Acknowledgements}

We thanked members of the theoretical and physical chemistry group, the chemistry department, Ahmadu Bello University Zaria. We sincerely appreciate David Arthur, Abdulateef Jimoh, Abdulfatai Usman, and Jonh Philip Ameji for their technical support and advice in the course of this study.

\section{Authors' contributions}

$\mathrm{AU}$ and OSB conceived, analyzed and interpreted the results. GAS, SU, and OSB performed the computational study and wrote the paper. All authors have read and approved the manuscript.

\section{Funding}

The authors received no funds.

\section{Availability of data and materials}

All data and material are available upon request.

\section{Ethics approval and consent to participate}

Not applicable.

\section{Consent for publication}

Not applicable.

\section{Competing interests}

No competing interests.

\section{Author details}

'National Agency for Food and Drug Administration and Control (NAFDAC), Abuja, Nigeria. ${ }^{2}$ Department of Chemistry, Ahmadu Bello University, Zaria, Nigeria.

Received: 8 October 2020 Accepted: 3 February 2021

Published online: 10 March 2021

\section{References}

1. Mavel S, Mincheva Z, Méheux N, Carcenac Y, Guilloteau D, Abarbri M (2012) QSAR study and synthesis of new phenyltropanes as ligands of the dopamine transporter (DAT). Bioorg Med Chem 20(4):1388-1395

2. Olasupo SB, Uzairu A, Shallangwa GA, Uba S (2020) Chemoinformatic studies on some inhibitors of dopamine transporter and the receptor targeting schizophrenia for developing novel antipsychotic agents. Heliyon 6(7):e04464

3. Li P, Snyder GL, Vanover KE (2016) Dopamine targeting drugs for the treatment of schizophrenia: past, present and future. Curr Top Med Chem 16(29):3385-3403

4. Nikiforuk A, Kalaba P, llic M, Korz V, Dragačević V, Wackerlig J (2017) A novel dopamine transporter inhibitor CE-123 improves cognitive flexibility and maintains impulsivity in healthy male rats. Front Behav Neurosci 11:222

5. Dolder PC, Müller F, Schmid Y, Borgwardt SJ, Liechti ME (2018) Direct comparison of the acute subjective, emotional, autonomic, and endocrine effects of MDMA, methylphenidate, and modafinil in healthy subjects. Psychopharmacology 235(2):467-479

6. Gong L, Yin Y, He C, Ye Q, Bai F, Yuan Y (2017) Disrupted reward circuits is associated with cognitive deficits and depression severity in major depressive disorder. J Psychiatr Res 84:9-17

7. Stroup TS, Marder S (2015) Pharmacotherapy for schizophrenia: acute and maintenance phase treatment. UptoDate July

8. Ferreira LG, Dos Santos RN, Oliva G, Andricopulo AD (2015) Molecular docking and structure-based drug design strategies. Molecules. 20(7):1338413421
9. Hehre WJ, Huang WW (1995) Chemistry with computation: an introduction to SPARTAN. Wavefunction, Inc, Irvine

10. Olasupo SB, Uzairu A, Shallangwa GA, Uba S (2020) Profiling the antidepressant properties of Phenyl piperidine derivatives as inhibitors of serotonin transporter (SERT) via cheminformatics modeling, molecular docking and ADMET predictions. Sci Afr 9:e00517

11. Lipinski CA (2016) Rule of five in 2015 and beyond: target and ligand structural limitations, ligand chemistry structure and drug discovery project decisions. Adv Drug Deliv Rev 101:34-41

12. Penmatsa A, Wang KH, Gouaux E (2013) X-ray structure of dopamine transporter elucidates antidepressant mechanism. Nature 503(7474):85-90. https://doi.org/10.1038/nature12533

13. Babatunde S, Adamu O, Gideon U, Sani S (2020) QSAR modeling, molecular docking and ADMET / pharmacokinetic studies : a chemometrics approach to search for novel inhibitors of norepinephrine transporter as potent antipsychotic drugs. J Iran Chem Soc 17(8):1953-1966. https://doi.org/10.1 007/s13738-020-01902-5

14. ul Hassan SS, Zhang W-D, Jin H, Basha SH, Priya SVSS (2020) In-silico antiinflammatory potential of guaiane dimers from Xylopia vielana targeting COX2. J Biomol Struct Dyn 1:1-15. https:/doi.org/10.1080/07391 102.2020.1815579

15. Daina A, Michielin O, Zoete V (2017) SwissADME: a free web tool to evaluate pharmacokinetics, drug-likeness and medicinal chemistry friendliness of small molecules. Sci Rep 7:42717. https://doi.org/10.1038/ srep42717

16. Yang H, Lou C, Sun L, Li J, Cai Y, Wang Z (2019) admetSAR 2.0: web-service for prediction and optimization of chemical ADMET properties. Bioinformatics 35(6):1067-1069

17. Pires DEV, Blundell TL, Ascher DB (2015) pkCSM: predicting small-molecule pharmacokinetic and toxicity properties using graph-based signatures. J Med Chem 58(9):4066-4072

18. Cheminformatics M (2018) Calculation of molecular properties and bioactivity score. Comput software] Retrieved from http://www.molinspira tion.com/cgi-bin/properties.

19. Qing X, Lee XY, De Raeymaecker J, Tame JRH, Zhang KYJ, De Maeyer M (2014) Pharmacophore modeling: advances, limitations, and current utility in drug discovery. J Receptor Ligand Channel Res 7:81-92

20. Rawn JD, Ouellette RJ (2018) Organic chemistry: structure, mechanism, synthesis. Academic Press, Cambridge

21. Mpiana PT, Tshibangu DST, Kilembe JT, Gbolo BZ, Mwanangombo DT, Inkoto CL (2020) Identification of potential inhibitors of SARS-CoV-2 main protease from Aloe vera compounds: a molecular docking study. Chem Phys Lett 754:137751

22. Ye Z, Yang Y, Li X, Cao D, Ouyang D (2018) An integrated transfer learning and multitask learning approach for pharmacokinetic parameter prediction. Mol Pharm 16(2):533-541

23. Hassan M, Ashraf Z, Abbas Q, Raza H, Seo S-Y (2018) Exploration of novel human tyrosinase inhibitors by molecular modeling, docking and simulation studies. Interdiscip Sci Comput Life Sci 10(1):68-80

24. Aswathy L, Jisha RS, Masand VH, Gajbhiye JM, Shibi IG (2018) Design of novel amyloid $\beta$ aggregation inhibitors using QSAR, pharmacophore modeling, molecular docking and ADME prediction. In Silico Pharmacol 6(1):12

25. Olasupo SB, Uzairu A, Adamu GS, Uba S (2020) Computational modeling and pharmacokinetics/ADMET study of some arylpiperazine derivatives as novel antipsychotic agents targeting depression. Chem Afr 3:1-10

26. Daina A, Zoete V (2016) A boiled-egg to predict gastrointestinal absorption and brain penetration of small molecules. ChemMedChem 11(11):11171121

27. Roy S, Samant LR, Chowdhary A (2015) In silico pharmacokinetics analysis and ADMET of phytochemicals of Datura metel Linn. and Cynodon dactylon Linn. J Chem Pharm Res 7:385-388

28. Ertl P, Schuffenhauer A (2009) Estimation of synthetic accessibility score of drug-like molecules based on molecular complexity and fragment contributions. J Cheminform 1(1):8

29. dos Santos KLB, Cruz JN, Silva LB, Ramos RS, Neto MFA, Lobato CC (2020) Identification of novel chemical entities for adenosine receptor type 2A using molecular modeling approaches. Molecules 25(5):1245

\section{Publisher's Note}

Springer Nature remains neutral with regard to jurisdictional claims in published maps and institutional affiliations. 